\title{
Thinking Creatively; Thinking Critically
}

\author{
Julie C. FORRESTER \\ English Department, Chu Hai College of Higher Education \\ Riviera Gardens, Tsuen Wan, New Territories, Hong Kong SAR, China \\ Tel: 852-2482-6880Ｅ-mail: jforrester@chuhai.edu.hk
}

\begin{abstract}
The development of creative and critical thinking is seen as an encouragement to independent and student-centred learning. But what exactly do we mean when we talk about creative and critical thinking? When and why did these terms come into prominence in modern education? This paper will compare and consider some of the diverse but not universally agreed definitions of these widely used terms. The language and literature classroom will be offered as an example in order to demonstrate ways of putting these approaches into practice. Finally the paper will close with a discussion of the application of critical and creative thinking in the Hong Kong context.
\end{abstract}

\section{Introduction: Creative and Critical Thinking}

The developments of creative and critical thinking are complementary, and both encourage independent and student-centred learning (Fisher, 1990). But what exactly do we mean when we talk about creative and critical thinking? When and why did these terms come into prominence in modern education, and how can we encourage these types of thinking?

'Critical thinking' is defined in many different ways, with no universally agreed definition (Brookfield, 1987; Cassel \& Congleton, 1993) and in the same way, the term 'creativity' is so widely used that there are diverse definitions (Lucas, 2001; Cropley, 2001) - which may in part be because researchers admit that we cannot yet fully explain the creative power of the brain (Sternberg, 1999). This paper will compare and consider some of the diverse but not universally agreed definitions of these widely used terms. The language and literature classroom will be offered as an example in order to demonstrate ways of putting these approaches into practice. Finally the paper will close with a discussion of the application of critical and creative thinking in the Hong Kong context.

\section{Creativity and Creative Thinking}

America in the 1950's was a time of great competition to be the first in space, and this competitiveness sparked a greater interest in creativity. If the early successes of the Russians could be explained in terms of their greater creative abilities, then American politicians could at least save face by investing money into creativity research, thereby demonstrating that American education was being changed to produce students who would be more 'creative' (Smith, 1959; Vernon, 1970). A second impulse towards creative thinking in the West was the move towards a 'student-centred' approach and away from a focus on 'testing' and 'rote-learning'; this development was encouraged by business interests seeing the value of a move away from expectations of life-long employment and towards 'flexible employment' and 'life-long learning', creating cultures of innovation and change (Ekval, 1996).

Creativity involves being able to generate new, varied and unique ideas. Gardner (1993) defines creativity as 'the ability to solve problems and fashion new products and to raise new questions'. But it may not be enough merely to generate ideas: creativity is often defined in terms of its importance to others. Thus Gruber \& Wallace (1999) say that a creative idea 'must be new and must be given value by some external criteria'; Robinson (2001) describes creativity as 'imaginative processes with outcomes that are original and of value'; Fisher (2002) reminds us that creativity is of value in education because it adds to human knowledge, even if the value of the new ideas is not recognized at the time.

Are humans naturally creative thinkers? The question of how natural creative thinking is to us will be reconsidered in the Hong Kong context later in this paper, but for now let it be enough to point out that young children have not yet learned how the world is 'supposed' to be', and so they are less constrained by judgment, will accept far more divergent and open-ended possibilities and are perhaps more willing to think laterally than young adults; so for example young children would probably not find the idea of their parents flying round the room to be as surprising as we might, (unless we are Harry Potter fans) because they have not been taught 'how (or 'how not') to think'. Children may also use the right side of their brains more, whereas maturity encourages the cognitive links in the brain to develop in such a way as to encourage critical, left-brain thinking. 


\section{Critical Thinking}

Critical thinking is defined in the Delphi Report of Critical Thinking (American Philosophical Association, 1990) as 'purposeful self-regulatory judgement', which manifests itself in giving reasoned consideration to the evidence, methods and conceptual structures within which a decision is made about what to believe or what to do. Thus, the key characteristics of critical thinking are both inductive and deductive reasoning, problem-solving, and 'reflective skepticism' (Tiwari, Chan, Sullivan, Dixon \& Tang, 1999.) A successful critical thinker should be able to analyse and evaluate major alternative points of view, to explain assumptions and reasons and to identify salient arguments (Facione \& Facione, 1994).

Critical thinking supports as well as follows creative thinking because once the focus has been widened by creative thinking, then critical thinking serves to evaluate ideas, which can be accomplished by narrowing the focus again to catalogue ideas and identify the most reasonable ones, or those most likely to succeed (Ruggiero, 1999).

Encouraging students to think critically involves, among other things, helping them to distinguish opinions from facts, to evaluate evidence, and to avoid shallow and illogical thinking. This approach is very important in helping to avoid (by recognizing) manipulation, which in turn can allow intellectual independence and creativity to flourish (Browne \& Keely, 1993; Mayfield, 1997; Paul, 1995).

For a learning environment to encourage the development of critical thinking, Meyers (1986) considers that four elements need to be present: a) the stimulation of students' interest, b) the creation of meaningful discussion, c) the exposure to the thoughts and views of others, and d) the fostering of a supportive and trusting atmosphere. Meyers feels that obtaining and holding the students' interest is the first, vital element, because once their interest is aroused, students can be guided into thinking critically and this will develop their confidence in their analytical and problem-solving abilities. The second stage of meaningful discussion, debate and questioning, allows students to develop the mental structures necessary for critical thinking, and the third stage of exposure to contrasting viewpoints clarifies their own attitudes as well as helping students move on to reasoning from multiple perspectives. The fourth stage, an atmosphere of trust and support, is essential before students will dare to let go of biases and try out new ways of thinking.

\section{Summary of the Differences between Critical and Creative Thinking}

This chart follows Fisher (2002).

\begin{tabular}{|l|l|}
\hline Creative Thinking & Critical Thinking \\
\hline Right-brain & Left-brain \\
\hline An answer & The answer \\
\hline Open-ended & Closed \\
\hline Associative & Linear \\
\hline Speculating & Reasoning \\
\hline Intuition & Logic \\
\hline Yes and & Yes but \\
\hline Generative & Analytic \\
\hline Divergent & Convergent \\
\hline Lateral & Vertical \\
\hline Possibility & Probability \\
\hline Suspended judgement & Judgement \\
\hline Hypothesis forming & Hypothesis testing \\
\hline Subjective & Objective \\
\hline Primary schoong & Seconty Sching? \\
\hline
\end{tabular}

Primary schooling?

Secondary Schooling?

While it is possible to differentiate critical and creative thinking, as does Fisher (2000), it is the argument of this paper that such a distinction is not necessarily helpful in the classroom, because students need to think in both creative and critical ways and therefore to teach or encourage one style of thinking only may be counter-productive. Instead, an approach is needed which can combine critical and creative thinking.

\section{An attempt to combine creative and critical thinking}

The challenge in education, if we are to help students cope with a changing world, is to develop people who can think in different ways from those of the past. At all levels in education, creative thinking should be encouraged, for, as Fisher points out (1987), problem solving and personal intelligence both depend on creativity. Sternberg \& Lubart (1999) have 
shown that students' academic performance improves when they are assessed in ways that value and recognize their creative abilities. Critical thinking too is equally important in education in the modern world, not least to help students evaluate the mass of information now available via sources such as the Internet and the mass media. If students are to be able to rise above the mere reproduction of others' ideas to the level where they can contribute new ideas of their own, they need to be able to draw on both critical and creative thinking.

An approach which combines both creative and critical thinking can encourage students to take the time to produce many ideas and arguments, to ask penetrating questions, to recognize the validity of arguments - even if those arguments might mean challenging even previously held viewpoints. While it is common to separate analytical or critical thinking from intuitive or creative thinking, both creative and critical approaches are essential for our thinking to be effective, and in an economy where people are expected to be both skilled and adaptable in the workplace, it is a duty of education to help students prepare for this necessary flexibility of thinking.

In order to show the relationship, and inter-change between different types of thinking and learning, the next section will briefly discuss research on levels of learning and how these levels of learning appear in the classroom.

\section{Levels of learning}

Bloom's Taxonomy (1956) divided the way people learn into three overlapping domains of affective (feelings, preferences and values), psychomotor (physical and perceptual activities and skills) and cognitive (thinking, evaluating and synthesizing information). It is the cognitive domain which emphasizes intellectual outcomes, and as such, this is the domain which is of most concern in language learning. Bloom divided the cognitive domain into six categories or levels, which he represented in a triangle, with the largest section at the base. This section he called knowledge, recall or recognition of facts. Bloom found that over $95 \%$ of test questions that students encounter require them to think only at this basic level. The second level is comprehension or understanding, which involves interpretation and classification of ideas, and the beginning of critical thinking. Then comes application, or using learned material in new situations, which involves problem-solving. The fourth level is analysis, the ability to separate material into component parts and show the relationships between those parts. Level five, according to Bloom, is synthesis (the ability to put ideas together in new ways, to innovate and think creatively). Level six, at the apex of the triangle, since in Bloom's opinion it is the most difficult, is evaluation or judgement (the ability to judge the worth of ideas against stated criteria by reviewing and asserting evidence, then making appropriate judgements: another aspect of critical thinking.)

Since Bloom's work first appeared, research has confirmed this taxonomy of learning levels as a hierarchy, with the exception of the two highest levels. It is presently unclear if synthesis and evaluation should be reversed, (that would mean that evaluation is less difficult to accomplish than synthesis) or whether synthesis and evaluation are at the same level of difficulty but use different cognitive processes. Both evaluation and synthesis depend on analysis - evaluation requires a comparison while synthesis requires re-arranging. This is similar to the distinction between critical and creative thinking - both are valuable while neither is superior. Students can 'know' about a topic or subject at different levels. While Bloom showed that most exams test (and many classroom teachers operate at) the lower levels of the taxonomy, research has shown that students remember more when they have learnt the topic at the higher levels of the taxonomy: in other words, within the human brain, more connections have been made.

Across the curriculum, it is possible to make use of the ideas behind Bloom's taxonomy by encouraging a much broader focus than on only lower level thinking skills. To demonstrate this in a classroom setting, a question focusing on knowledge (Bloom's lowest level) might be as basic as 'what is the definition of ...?' and a level two (comprehension) question, common in multiple-choice exams, might ask 'which is the best answer...?'. However, reading comprehension at this level can also be assessed by a different question, such as 'how would you compare or contrast..?' which already opens up more possibilities of demonstrating understanding of facts and ideas by organizing the data, and may well also lead to discussion between students which is leading into a level three (application) question such as 'how would you show your understanding of..?' Class discussions may make use of questions such as 'what inference can you make from...?', which illustrate Bloom's fourth level, analysis. Synthesis and evaluation (Bloom's top two levels) could be developed through questions such as 'can you predict the outcome if...? or 'can you elaborate on the reason...?' (synthesis questions) and 'do you agree with the actions/outcomes?', or 'what choice would you have made?' (evaluation questions).

In summary, while lower level questions (knowledge comprehension and simple application levels) are useful and appropriate for reviewing or summarizing content, evaluating students' preparation and comprehension, and diagnosing their strengths and weaknesses, it is the higher level skills (analysis, synthesis and evaluation) which require complex application and which are therefore most appropriate for encouraging students to think more deeply, for encouraging discussions and stimulating students to seek information on their own. In addition, lower-level skills tend to be demonstrated by asking and answering closed questions (that is, where there are a limited number of acceptable answers). However, open questions (where there are many acceptable answers, some of which may not even be anticipated by the instructor) are more frequent when the higher-level skills are being used. Sometimes there is no one, 
right answer - sometimes many reasons, solutions and possibilities can co-exist; and discussion can encourage this tolerance of ambiguity. In literature, for example, a word or phrase in a poem may not just mean one thing but could draw upon and include many possible meanings, and therefore, have more than one possible interpretation.

\section{An Example of Developing Critical and Creative Thinking: the Language and Literature Classroom}

One method to encourage both critical and creative processes in the language and/ or literature classroom (which can also be used in other disciplines) is to use a 'process writing' approach; that is, not to insist that any piece of writing is completed in one go, without involving a drafting process to modify, re-organise and develop the writing (Watkins-Goffman, 1993; Goffman \& Velazquez, 1993). This allows time for creative thinking, (using techniques such as brain-storming or free writing to provide a new 'way in' to a topic; providing gestation time for ideas to emerge; using group-work as an active support for students doing things as individuals) and a period of critical thinking (which can be self-analysis but also, if students are involved in giving feedback on each other's writing, allows greater opportunities for comparison, analysis and evaluation). Process writing can help the flow of ideas (through techniques such as brainstorming) and develop communication skills (as students comment on, justify, re-organise and re-write their pieces).

Developing out of the technique of process writing is a complementary approach, that of dialogues or process journaling, in which students write to the teacher, and/or to each other. The journals are typically used to record students' feelings about a piece of writing, task or course being studied, and they are an effective tool in encouraging students to reflect on what they are learning. Because journal writing often acts as an accompanying but independent writing project throughout a course, it can encourage students to let go of the 'product' approach and so supports process writing. Journals can also encourage a new element in communication which can allow more personal comments or questions that students might be reluctant to voice in a class. Students have multiple learning styles and multiple writing styles (Elbow, 1973) and journaling allows a more diverse approach and perhaps a more varied repertoire which can also encourage them into different thinking styles, and so again allow both creativity and critical thinking to flourish.

Communication skills are not only developed through writing, but also by speaking and listening practice. These 'life-skills' have been encouraged as a possible method to curb the current high suicide rate among young people in Hong Kong (South China Morning Post, 23 March 2002), as being activities which can promote students' self confidence and positive outlook and also perhaps (through more effective listening skills), help to detect despair in others. In addition, group work encouraging creative solutions to problems may help students to 'open-up' to each other, while a critical thinking approach can offer alternative viewpoints and attitudes.

Literature can also offer a different viewpoint on life, because it can raise awareness of, and encourage discussion of (and hopefully, research into) different lifestyles, different ways of thinking and acting, different attitudes and beliefs. In this way, literature can be used to encourage critical thinking, and can even form the basis of a challenge to prejudices or previously held viewpoints, because it allows the reader to dip into other people's lives in different cultures and periods of history, showing that even if the society we live in imposes certain expectations about behavior, other roles may be possible. In this way, reading can offer a 'time-out' to a different world - perhaps not such a bad thing when so many of Hong Kong's young people have so many stresses to cope with.

Using literature in the classroom does not necessarily mean reading an entire novel. Poetry and short stories are an extremely valuable for the development of language, and to encourage critical and creative thinking. Different stories and poems can present different challenges, so that while some may be linguistically demanding and can therefore be used to extend students' vocabulary, (which could then be re-cycled in a creative writing class, for example) others may be conceptually more demanding, perhaps requiring a leap of the imagination or an appreciation of how many ideas or images can be compressed into a small space. With this type of story or poem, re-reading is likely to bring deeper understanding and new insights, and the possibilities of fruitful discussion as students evaluate and analyse alternative points of view. With all stories, poems and all pieces of writing, the activity that precedes the reading is crucial to encourage interest, as well to encourage thinking 'around' the topic in creative and critical ways.

Any and all reading helps to develop vocabulary, brings a greater awareness of grammar and possible ways of expressing ideas, and hones the sub-skills of reading (such as prediction, guessing from context, skimming and scanning for information) which are essential in our daily lives, in and out of the classroom. Reading longer works (whether fictional or factual) can also encourage greater reading speed (an extremely useful skill in the age of mass information) as long as students are encouraged to realize that they can gain a great deal from any text even if they cannot understand every single word. Without some form of language it is almost impossible to express complex ideas, but language feeds those ideas so that our communication skills can go on developing along with our critical and creative faculties.

\section{The Hong Kong context}

In Hong Kong, non-core academic subjects are being merged into liberal studies, which emphasises interdisciplinary critical thinking in preparation for higher education. The current education reforms also emphasise classroom-based 
creativity, which the Hong Kong Curriculum Development Council (CDC) in its comprehensive view of creativity describes as "the ability to generate original ideas and solve problems appropriate to the contexts" (CDC, 2001). Teachers' curriculum guides (CDC, 2002a) for the five key-learning areas of Chinese and English Language, Arts, Mathematics and Science, provide detailed and extensive suggestions of how students' 'learning capacity' is strengthened where teachers' give class-time to developing students' specific creative abilities.

However such detailed and explicit guidance also carries several implicit assumptions: first that Hong Kong classroom teachers require such guidance; second, that Hong Kong students are not innately 'creative' and require to be 'taught' to be so, and third, that such education reforms are attained 'top-down' through monitoring the implementation of a detailed and controlled centralized curriculum. Forrester's 2006 research into this issue shows that in fact teachers do display creativity-enhancing techniques. His findings show that "students' verbal creativity correlated significantly and positively with teachers' teaching technique of motivation in mastery of knowledge. Moderately positive correlations were found between teachers' creative personality and their creativity teaching techniques, in particular promoting flexibility in thinking, using students' ideas, suspended judgment, promoting motivation in mastery of knowledge, promoting independent learning, and providing opportunities for trial. Results further showed that two factors among the creativity fostering teaching techniques were significant predictors of students' verbal creativity: these factors included promoting motivation in mastery of knowledge, and promoting student self-evaluation."

Forrester's findings of a moderately strong association between students' verbal creativity scores and teachers' creativity fostering teaching techniques indicates that - as predicted in the system theory of Csikszentmihalyi (1996) teachers are significant gatekeepers in the development of their students' creative potential. Forrester also points out that the same findings also support Amabile's (1996) componential theory of creativity, for these teachers appear able to motivate students to work towards mastery of knowledge, encourage students to devote more time and effort to study and thus increase their intrinsic motivation.

\section{Conclusion}

Education should focus not only on core skills and knowledge but also on teaching and practicing creative and critical thinking skills, because these are the skills that will encourage life-long learning and personal development. As Fisher (2002) comments, creative and critical thinking are both important because we need instruction as well as reason in our thinking: critical thinking is necessary to judge those new ideas, processes and products which have been generated by creative thinking.

If the educational community is to encourage both creative and critical thinking, then students must be given the motivation to think, the time to develop ideas, and the collaboration and support of a learning community that provides information, feedback and encouragement. Creative teachers will encourage creative learners, but those teachers also need to employ critical thinking to assess their own teaching methods and their students' learning styles. Education needs teachers and students who can connect ideas, see similarities and differences, and above all, be flexible and curious in their thinking. Creative and critical thinking skills involve and affect both teachers and learners: they are brought together into sharing the responsibility for effective learning.

\section{References}

Amabile, T. M. (1966). Creativity in context. Boulder: Westview Press.

American Philosophical Association. (1990). Critical Thinking: A statement of expert consensus for purposes of educational assessment and instruction, Recommendations prepared for the Committee on Pre-College Philosophy. ERIC Doc. ED 315423.

Bloom, B. et al. (1956). Taxonomy of Educational Objectives: The classification of educational Goals. New York: McKay.

Csikzentmihalyi, M. (1996). Creativity: flow and the psychology of discovery and invention. New York: Harper Collins.

Brookfield, S.D. (1987). Developing Critical Thinkers: Challenging adults to explore alternative ways of thinking and acting. San Francisco: Jossey-Bass.

Browne, N. \& Keely, S. (1993). Asking the Right Questions: A guide to critical thinking. Englewood Cliffs, New Jersey: Prentice-Hall.

Cassel, J.F., \& Congleton, R.J. (1993). Critical Thinking: An annotated bibliography. (Metuchen, N.J.: The Scarecrow Press Inc.

Cropley, A.J. (2001). Creativity in Education and Learning: A guide for teachers and Educators. London: Kogan Page.

Curriculum Development Council. (2001). Learning to learn: The way forward in curriculum development Hong Kong: HKSAR Government Printer. 
Curriculum Development Council. (2002). Chinese Language education: Key learning area curriculum guide (Primary 1 - Secondary 3) Hong Kong: HKSAR, Government Printer.

Elbow, P. (1973). Writing Without Teachers. Oxford: Oxford University Press.

Ekvall, G. (1996). Organisational Climate for Creativity and Innovation. European Work and Organisational Psychology 5. 105-123.

Facione, N.C. \& Facione, P.A. (1994). Holistic Critical Thinking Scoring Rubric. Millbrae, CA.: The California Academic Press.

Fisher, R. (Ed.). (1987). Problem Solving in Primary Schools. Oxford: Basil Blackwell.

Fisher, R. (1990). Teaching Children to Think. Cheltenham: Nelson Thornes.

Fisher, R. (2002). Creative Minds: Building communities of learning for the creative age. Paper at Thinking Qualities Initiative Conference, Hong Kong Baptist University, June 2002.

Forrester, V. (2006). Is Creativity Teacher or Curriculum Based in Hong Kong? Paper at Lifelong Learning Conference, Rockhampton, Australia.

Gruber, H.E., \& Wallace, D.B. (1999). Understanding Unique Creative People at Work. In R.J. Sternberg (1999). Handbook of Creativity. Cambridge: Cambridge University Press.

Gardener, H. (1993). Creating Minds. (New York: Basic Books.

Lucas, B. (2001). Creative Teaching, Teaching Creativity and Creative Learning. In A. Craft, B. Jeffery, \& M. Leibling (Eds.) (2001). Creativity in Education. London: Continuum.

Mayfield, M. (1997). Thinking for Yourself: Developing critical thinking skills through reading and writing. Belmont, CA.: Wadsworth Publishing Co.

Meyers, C. (1986). Teaching Students to Think Critically. San Francisco: Jossey-Bass.

Paul, R. (1995). Critical Thinking: What every person needs to survive in a rapidly changing World. Rohnert Park, CA.: Center for Critical Thinking and Moral Critique, Sonoma State University.

Robinson, K. (2001). Out of our Minds: Learning to be creative. Oxford: Capstone.

Rowling, J.K. (2007). Harry Potter and the Deathly Hallows. London: Bloomsbury Books.

Ruggiero, V.C.(1999). Becoming a Critical Thinker. St. Charles, III.: Houghton Mifflin.

Smith, P. (Ed.). (1959) Creativity. New York: Hastings House.

Sternberg, R.J. (Ed.). (1999) Handbook of Creativity. Cambridge: Cambridge University Press.

Sternberg, R.J., \& Lubart, T.I. (1999). The Concept of Creativity: Prospects \& paradigms. In R.J. Sternberg (Ed.). (1999). Handbook of Creativity. Cambridge: Cambridge University Press.

Tiwari, A., et al. (1999). Enhancing Students' Critical Thinking through Problem-Based Learning. In Marsh, J. (Ed.). (1999). Implementing Problem-Based Learning. Hong Kong: Proceedings of the First Asia Pacific Conference on Problem Based Learning.

Yeung, L., \& Hui, P. (2002). Call for action to curb suicides. Hong Kong: South China Morning Post, March 23, 2002.

Vernon, P.E. (Ed.). (1970). Creativity: Selected readings. Harmondsworth: Penguin.

Watkins-Goffman, L. et al. (1993). Making Your Point. A Process Approach to Argumentation. Mass.: Heinle \& Heinle. 